\title{
Article
}

\section{Preparing the "New" Biologist of the Future: Student Research at the Interface of Mathematics and Biology}

\author{
Sarah I. Duncan, Pamela Bishop, and Suzanne Lenhart
}

\author{
National Institute for Mathematical and Biological Synthesis, University of Tennessee, Knoxville, TN \\ 37996
}

Submitted March 15, 2010; Revised June 9, 2010; Accepted June 11, 2010

Monitoring Editor: John Jungck

\begin{abstract}
We describe a unique Research Experience for Undergraduates and Research Experience for Veterinary students summer program at the National Institute for Mathematical and Biological Synthesis on the campus of the University of Tennessee, Knoxville. The program focused on interdisciplinary research at the interface of biology and mathematics. Participants were selected to work on projects with a biology mentor and a mathematics mentor in an environment that promoted collaboration outside of the students' respective disciplines. There were four research projects with teams of four participants and two faculty mentors. The participants consisted of a mixture of 10 undergraduates in biology- and mathematics-related disciplines, four veterinary students, and two high-school teachers. The activities included lectures on both the biological and mathematical backgrounds of the projects, tutorials for software, and sessions on ethics, graduate school, and possible career paths for individuals interested in biology and mathematics. The program was designed to give students the ability to actively participate in the scientific research process by working on a project, writing up their results in a final report, and presenting their work orally. We report on the results of our evaluation surveys of the participants.
\end{abstract}

\section{INTRODUCTION}

According to "A New Biology for the 21st Century", (National Research Council [NRC], 2009), both biology and science education are undergoing major change. This change reflects the breakthrough discoveries and new technology revolutions that have emerged over the last decade (American Association for the Advancement of Science, [AAAS] 2010). The NRC (2009) defines the idea of what the new biologist of the twenty-first century should be: "The New Biologist is not a scientist who knows a little bit about all disciplines but a scientist with deep knowledge in one and a "working fluency in others." The biologist should have "highly developed quantitative skills" and be "well versed

DOI: $10.1187 /$ cbe.10-03-0025

Address correspondence to: Sarah I. Duncan (sduncan7@utk.edu).

(C) 2010 S. I. Duncan et al. CBE-Life Sciences Education (C) 2010 The American Society for Cell Biology. This article is distributed by The American Society for Cell Biology under license from the author(s). It is available to the public under an AttributionNoncommercial-Share Alike 3.0 Unported Creative Commons License (http://creativecommons.org/licenses/by-nc-sa/3.0). to facilitate dialogue with other researchers." This report focuses on undergraduate education and the change required to facilitate student success in the field of science, particularly in the dynamic discipline of biology.

Because biology is in itself inherently complex and requires researchers to be knowledgeable in many areas of study, researchers must have in-depth understanding of not only their respective disciplines but also computational and quantitative skills (NRC 2003). The practice of biology, or any science, involves interpretation of large, diverse sets of data that require mathematical or statistical tests. Therefore, it is important for students to build a strong foundation in mathematics, which provides the essential tools to analyze complex data, make models, and predict relationships (NRC, 2003, 2009). Thus, close collaborations between mathematicians and biologists are giving new approaches to biological questions and providing new avenues of innovation for mathematics (NRC, 2009).

Students must actively participate in the scientific process through research to gain the knowledge needed in their own discipline and the ability to understand and collaborate with other knowledgeable colleagues in various fields. Two major goals for a quantitative undergraduate education, according to the AAAS Visions and Change report (2010), are to engage 
students in the scientific process and provide rich activelearning opportunities that promote science as a "vibrant and active field." In fact, students themselves report the need for providing more opportunities outside of the classroom and more opportunities to develop the quantitative skills necessary to be successful in research (NRC, 2009). New quantitative training methods are also included in recommendations given by the Association of American Medical Colleges and the Howard Hughes Medical Institute (2009) to better prepare medical students. In response to these recent reports and as part of its mission to train scientists working at the interface of mathematics and biology, the National Institute for Mathematical and Biological Synthesis (NIMBioS) sponsored a unique summer Research Experience for Undergraduates (REU) and Veterinary Students Program (REV).

As part of our education mission, in 2009 NIMBioS planned to host an REU summer program with students majoring in mathematical sciences or biology. The program was designed to emphasize research at the interface of mathematics and biology. Because NIMBioS is funded through the first cooperative agreement among National Science Foundation, the U.S. Department of Homeland Security, and the U.S. Department of Agriculture, it was natural that one of the members of the NIMBioS Board of Directors, Dr. Gary Smith, from the University of Pennsylvania School of Veterinary Medicine, suggested that we include veterinary students in our summer research program. After the NIMBioS Board approved the idea, Suzanne Lenhart and Sarah Duncan organized our 2009 REU/REV summer program.

\section{PROGRAM DETAILS}

The REU/REV summer program at NIMBIoS in 2009 had 16 participants, consisting of 10 undergraduates, four veterinary students, and two high-school teachers. The participants came from a diverse group of biology and mathematics majors with backgrounds in disciplines such as agricultural sciences/natural resources, biological/biomedical sciences, engineering, veterinary medicine, computer science, statistics, and mathematics. Additionally, two local high-school teachers (one taught high-school biology, one taught high-school mathematics) from Clinton High School in Clinton, TN, participated in the program. The veterinary students were from the University of Tennessee, Michigan State University, Washington State University, and the University of Pennsylvania. The participants were divided into four groups for four interdisciplinary projects, and each group had a mathematics faculty mentor and a biology faculty mentor. The projects and their participants were:

1. Codon usage bias, four undergraduates (two mathematics majors and two biology majors)

2. Chemical defense modeling with mint plants (involved some field work), two undergraduates (one mathematics major and one biology major), two high-school teachers

3. Modeling and control of ticks in Fairfield Glade Retirement Community, two undergraduates (two mathematics majors), two veterinary students
4. Spatial clustering of campylobacteriosis in East Tennessee, two undergraduates (one mathematics major and one biology major), two veterinary students

The distribution of the undergraduate students included six females (two minority students) and four males. The four veterinary students were females (including one Native American participant).

The program spanned eight weeks in the summer of 2009, and most of the participants lived in shared university apartments at the University of Tennessee campus. Stipends of $\$ 3200, \$ 3500$, and $\$ 5000$ were paid to the undergraduates, veterinary students, and teachers, respectively. The cost of transportation to and from the program and housing (for those who wanted it) for the duration of the program were provided. We viewed this research experience as a $40-\mathrm{h}$ per week job for all of the participants involved. There were weekly meetings within the project groups, in addition to several meetings during the program that included all participants. The participants were expected to work both with their group and independently outside of their respective groups.

S.L. presented a few lectures introducing mathematical modeling to all participants at the beginning of the program. Lead mentors presented the biological backgrounds of the four research projects. Tutorial sessions on software including $\mathrm{R}$ (www.rproject.org) and MATLAB were also made available to the students. We provided some background on the scientific community through discussions about career opportunities, graduate school, and the academic tenure system. A discussion session on ethics in scientific research included ideas about publication practices and working with animal subjects. Early in the program students were trained by mentors, using examples on an individual basis, to use library databases such as Web of Science, to conduct scientific literature searches to ensure that students were able to find relevant information about their project topics. The training included meeting with mentors to discuss key points in the papers.

Students kept notebooks recording all of their work through the duration of the program. Frequent progress reports were given to Suzanne Lenhart through oral feedback sessions over the course of the eight weeks. In addition, participants also received training about giving professional presentations and writing papers by having discussions on these topics with their mentors. Participants submitted a written report discussing their research and presented their projects to an audience consisting of NIMBioS mentors, faculty, staff, and graduate students. Mentors and staff gave feedback on preliminary versions of the presentations and reports. The research mentors organized meetings for their groups to fit the goals of the project. However, participants in each group frequently met independently without their mentors.

Besides the training and research aspects of the summer program, social activities were also important. Sarah Duncan and Suzanne Lenhart organized social activities with the participants, and often the students themselves initiated social events within the group. Social gatherings organized by Sarah Duncan and Suzanne Lenhart included picnics at local parks, a hike in the Great Smoky Mountains National Park, a rafting trip, dinner parties, and lunches with mentors. These activities provided students with opportunities to 
interact with individuals outside of their respective project both on a personal and professional level.

\section{PROJECT DETAILS}

Participants were selected to work on one of four research projects. Descriptions of two of the projects are outlined below:

\section{Modeling Predictors of Geographic Distribution of Campylobacter Infections in East Tennessee (Mentors: Agricola Odoi/Suzanne Lenhart)}

Campylobacteriosis is a zoonotic disease caused by Gramnegative bacteria, Campylobacter jejuni, which is the most common bacterial cause of diarrhea in the United States. It is thought that the incidence of campylobacteriosis is higher in East Tennessee than the rest of the state and the nation. Therefore, this project investigated the spatial patterns of Campylobacter infections at various spatial scales in East Tennessee and modeled predictors of identified spatial patterns. Participants gained an understanding of the biology/epidemiology of the disease and were exposed to a number of spatial statistical techniques and software tools useful in investigating spatial disease patterns and spatial modeling. The findings of the project will be useful in guiding disease control strategies.

\section{Spatial Control of Ehrlichiosis, a Tick-borne Disease (Graham Hickling/Suzanne Lenhart)}

We give more details about this group to illustrate the process for learning about building a model. Graham Hickling and Suzanne Lenhart did not have the model structure decided in advance; they wanted the students to build the model with some input from their two mentors. The work started with doing literature searches and learning about using scientific databases for those who needed it. The focus of this group was the Amblyomma americanum, the Lone Star tick, which is the predominant tick species throughout the southeast United States. The importance of this tick has grown over the past few decades because of its role in the transmission of diseases, especially seen in the increase of cases of erlichiosis in the population. The key to Lone Star tick control begins with an understanding of its complex three-host life cycle and continues long term with successful management of the tick on its primary host, the white-tailed deer. Because we were concentrating on the tick problem in the Fairfield Glade retirement community near Knoxville, all six group members went on a field trip to see the mechanisms used to collect ticks (using drag cloths and dry ice tray procedure) and to examine the four-poster feeders, which apply acaricide to the feeding deer and can kill ticks on the deer. This field trip was a learning experience for the project team to become familiar with the area and set-up behind the project. The team started to build a discrete time model for ticks in a small area within the Fairfield Glade community. One student seemed surprised to see the mentors express differing opinions about features of the model, but it was good for students to experience discussions about what features to include. This gave the stu- dents the opportunity to witness researchers collaborating on the features of the model and coming to a compromise through discussion, which plays a large role in the scientific process. Our model included the distinct life stages of this tick population, and later we added spatial features of this community. The location of the feeders affected the death rates in the spatial and temporal model of difference equations. The region was divided into 80 spatial grid boxes. Data collected by J. Harmon (one of Graham Hickling's graduate students) at Fairfield Glade were used to estimate some of the parameters, while other parameter estimates were based on previous lone star tick modeling work (Haile and Mount, 1987). We formulated an economic criterion to evaluate various feeder placement scenarios that allow recommendations to be made to Fairfield Glade for four-poster feeder arrangements that minimize a combination of the cost of feeders and the cost of ehrlichia cases. The veterinary students learned about modeling, and one of them learned about the mathematical concept of vectors for the first time. We used the ideas of vectors in our model that was implemented in MATLAB. The mathematics students did most of the MATLAB coding to run simulations of the model. All the participants contributed ideas for the model; one of the veterinary students knew geographic information system well, which helped with constructing the spatial regions and their environmental features. All of the students were able to contribute in different ways, which promotes the goal of the program-to have students working with individuals outside of their respective disciplines. We are continuing this work because further optimization needs to be done; we were only able to analyze numerical simulations for a few scenarios with regard to specific placement of feeders corresponding to calculated economic costs.

\section{EVALUATION RESULTS}

Sarah Duncan and Suzanne Lenhart worked with Pam Bishop, the NIMBioS Evaluation Coordinator, to design web-based pre- and postsurveys to assess the impacts of the program on students' research skills, understanding of the scientific process, and ability to work with others outside of their respective disciplines.

Overall satisfaction with the program was high, with $100 \%$ of participants being "satisfied" or "very satisfied" with their experiences. All participants also indicated they would recommend the program to others. The majority of participants said the program met or exceeded their expectations, and that the workload was appropriate for the program. Most students worked $40 \mathrm{~h}$ per week. Participants were also highly satisfied with their mentors, indicating that they were skillful, helpful, and positively affected the research experience overall.

Participant self-ratings were on a scale of 1-5 (1 = Extremely poor and $5=$ Excellent) for pre- and postresearch skills (Table 1) and research-related knowledge (Table 2). A comparison of pre- and postprogram self-ratings showed that all participants experienced gains in research skills as a result of their experience. Participants were asked several questions before and after participating in the program to gauge how well they felt they could carry out several research-related skills. Analysis of pre- and postresponses 
Table 1. Average participant pre- and postprogram self-ratings of research skills on a scale of 1-5

\begin{tabular}{lcc}
\hline $\begin{array}{l}\text { How would you rate your ability } \\
\text { regarding the following research } \\
\text { skills? }\end{array}$ & Presurvey & Postsurvey \\
\hline $\begin{array}{l}\text { Integrating scientific theories with } \\
\quad \text { research }\end{array}$ & 3.0 & 3.8 \\
$\begin{array}{l}\text { Designing a research plan } \\
\text { Using research literature }\end{array}$ & 2.9 & 3.6 \\
Working collaboratively with other & 3.8 & 4.0 \\
$\quad$ researchers & 3.0 & 4.4 \\
Using mathematical tools or models & 3.0 & 3.6 \\
$\quad$ to describe a biological scenario & 3.5 & 4.1 \\
Orally presenting results & 3.4 & 3.7 \\
Writing about results & 3.8 & 4.1 \\
Analyzing data & 3.8 & 4.1 \\
Interpreting results & 3.4 & 3.9 \\
Average & & \\
\hline 1 = Extremely poor, $5=$ Excellent & & \\
\hline
\end{tabular}

showed that gains were reported in every skill on the survey, with an average rating for all skills at 3.4 on the presurvey and 3.9 on the postsurvey (on a scale of 1 being extremely poor at the skill and 5 being excellent at the skill). Participants showed the greatest skill gains in integrating scientific theories with research, designing research plans, and using research literature. Other skills enhanced by participation in the program included working collaboratively with other researchers, using mathematical tools or models to describe a biological scenario, and orally presenting research results (Table 1).

In addition to enhancing their research skills, participants also reported gains in knowledge about the research process. Participants were asked to rate their level of knowledge about several research-related topics both before and after participating in the program. Before the program, partici-

Table 2. Average participant pre- and postprogram self-ratings of research-related knowledge on a scale of 1-5

\begin{tabular}{lcc}
$\begin{array}{l}\text { How would you rate your level of } \\
\text { understanding in the following } \\
\text { areas? }\end{array}$ & Presurvey & Postsurvey \\
\hline $\begin{array}{l}\text { The nature of interdisciplinary } \\
\text { research collaborations }\end{array}$ & 2.9 & 4.1 \\
$\begin{array}{l}\text { The demands of a research career } \\
\text { in your discipline }\end{array}$ & 3.1 & 4.0 \\
$\begin{array}{l}\text { The nature of the research process } \\
\text { How current research ideas build } \\
\text { upon previous studies }\end{array}$ & 3.3 & 4.3 \\
$\begin{array}{l}\text { How scientists work on real } \\
\text { problems }\end{array}$ & 3.3 & 4.1 \\
$\begin{array}{l}\text { Possible career paths in your } \\
\text { discipline }\end{array}$ & 3.1 & 4.0 \\
$\begin{array}{l}\text { Ethical issues in research } \\
\text { Average }\end{array}$ & 3.2 & 3.8 \\
\hline \begin{tabular}{l}
$1=$ Extremely poor, 5 Excellent \\
\hline
\end{tabular} & 3.2 & 3.9 \\
\hline
\end{tabular}

pants on average rated themselves 3.2 on a 5 -point scale $(1=$ Extremely poor understanding of the topic, $5=$ Excellent understanding). After participation, the average rating was 4.0. Participants showed the greatest gains in understanding the nature of interdisciplinary research collaborations and the demands of a research career (Table 2).

\section{DISCUSSION}

The goal of this program was to expose students to the process of scientific research including the interdisciplinary nature of science and the importance of communication and collaboration in scientific research. We feel that this program contributed greatly to the training of these future "new biologists" and mathematicians who can work on interdisciplinary projects.

Teaching modeling with some simulation and statistical tools facilitated the research work. Presenting results in presentations and reports along with getting feedback from others helped to improve the communication skills of the participants. We saw the value of interdisciplinary teams with respect to mentors and participants contributing in different ways. The expertise of veterinary students in public health issues and knowledge of disease pathogens added greatly to the projects focused on modeling the spread of diseases. In addition, the veterinary students gained an appreciation of the usefulness of mathematics in their field. The high-school teachers learned research skills. They will carry this research knowledge back to their students along with details about research opportunities. The undergraduates gained research experience as well as a perspective on the interdisciplinary nature of science and the importance of being able to collaborate with individuals outside of their own disciplines.

The results of our evaluations show the positive experiences and training progress of our participants. We feel it is essential to the program to provide a holistic research experience encompassing personal and professional development. The ethics session in 2009 was based on proper handling and care of animal subjects. We will extend the ethics session to include ethics in the workplace and in the publication process. Diversity awareness will be a new session in which students will learn about diversity issues in science. We will continue to improve the program based on evaluation results from preceding years. We are planning to include mentor-based assessment of student learning gains to the evaluation of the program in the following years.

\section{ACKNOWLEDGMENTS}

We thank the National Institute for Mathematical and Biological Synthesis, National Science Foundation EF-0832858, for supporting this program, along with faculty mentors and participants for their hard work and dedication to the program. We also thank the anonymous reviewers for their helpful comments and suggestions. This research is IRB-Exempt as determined by the Internal Review Board at the University of Tennessee. 


\section{REFERENCES}

Association of American Medical Colleges and the Howard Hughes Medical Institute (2009). Scientific Foundations for Future Physicians. Report of the AAMC-HHMI Committee, Washington, DC.

American Association for the Advancement of Science (2010). Vision and Change in Undergraduate Biology Education: A Call to Action. Washington DC.
Haile, D. G., and Mount, G. A. (1987). Computer simulation of population dynamics of the lone tick, Amblyomrna (Acari: Ixodidae). J. Med. Entomol. 24, 356-369.

National Research Council (2003). BIO 2010: Transforming Undergraduate Education for Future Research Biologists. Washington, DC: National Academies Press.

National Research Council (2009). A New Biology for the 21st Century. Washington, DC: National Academies Press. 